Great Britain) at $10-11 \mathrm{~km}$. height a value of about $220^{\circ} \mathrm{K}$. which remains constant to at least $30 \mathrm{~km}$. From a few kilometres below $40 \mathrm{~km}$. upwards, the temperature increases until it reaches at $50-60 \mathrm{~km}$. more than $330^{\circ} \mathrm{K}$., whereupon it falls again, to a lower level than that of the stratosphere; the minimum, of about $200^{\circ} \mathrm{K}$., is reached between $70 \mathrm{~km}$. and $90 \mathrm{~km}$. From here onwards the temperature rises again ; at $100 \mathrm{~km}$. it is about $380^{\circ} \mathrm{K}$., at
$300 \mathrm{~km}$. it is in the neighbourhood of $1400^{\circ} \mathrm{K}$., and may increase still further with height.

Thanks to the rise in temperature from $40 \mathrm{~km}$., and again from about $90 \mathrm{~km}$. onwards, the density of the atmosphere is much greater above these heights than would be caused by gravity distribution if the temperature of the stratosphere remained constant. At $100 \mathrm{~km}$. it is of the order of $10^{12}$ molecules/c.c., at $300 \mathrm{~km}$. it is still $10^{10}$ molecules/c.c. F. A. Paneth.

\title{
Institution of Gas Engineers
}

$\mathrm{T}$ HF seventy-sixth annual general meeting of the Institution of Gas Engineers, held in London during June 6-9, was noteworthy as the centenary of the death of William Murdoch, the versatile Scot, who is acclaimed as the father of the British gas industry. Mr. Robert Robertson, engineer and manager of the Bristol Gas Co., presided.

In a symposium on the present and future prospects of the town's gas industry, eleven Dominion and Overseas engineers, describing the conditions in their own countries, revealed that the idea of distilling coal for lighting gas arose in several places, but it was recognized that no one deserves more credit than Murdoch for establishing the practicability of coal gas manufacture.

These contributions showed that in every country the rise of newer industries such as those of oil and electrical supply has exerted an influence on the use of gas in certain directions, accentuated by the greater efficiency of appliances. Nevertheless, the merits of a clean gaseous fuel has sufficed not merely to maintain but also to increase the consumption of gas even in those countries where all coal must be imported while hydro-electric power is abundant. The president of the Swiss Gas Association, for example, says that in spite of the great financial efforts of the electrical industry, the Swiss housewife appreciates the value of the gas flame with its instantaneous heat, its great power and quality of being visibly regulated within wide limits.

In Norway the need for coke has a dominating influence, and the gas industry can supply only 8 per cent of the country's needs. Large losses, apparently. have been incurred there by too optimistic investments of public funds in hydro-electric works in the erroneous belief that the power so generated might replace gaseous fuel.

The president's address-a review of the development of the gas industry-contained a notable announcement of a new departure in its policy of organized research. In this, the industry has been a pioneer, for thirty years ago-long before the days of research associations--the Institution began the practice of supporting co-operative research. During this time it has furthered a programme of research done at the University of Leeds, and the president's address referred to nearly fifty reports issued from this source. In the meantime, many gas undertakings, contractors and associations concerned with by-products have produced an increasing volume of experimental work. It is estimated that about a quarter of a million pounds in the aggregate is spent annually in development work. Nevertheless, such is the state of flux in the utilization of fuel that a widening of the organization of research is projected.
Until recently, investigation could be confined to established practice of making and using gas, but to-day the industry is seeking to widen the range of coals suitable for gas making and to convert these into solid, liquid and gaseous fuel in any desired proportion-even to complete gasification by the use of high-pressure technique. It is now proposed to establish a Gas Research Board supported by the subscriptions of gas undertakings and manufacturers of plant and appliances. The first president will be Sir David Milne Watson, and a director of research will be appointed. The Board will be constituted so as to qualify for Government grants if and when this is thought desirable. It is proposed to use the facilities available in existing institutions - at least in the immediate future. The functions of the Board will be: (1) the collection and dissemination of information concerning research of interest to the gas industry, (2) the provision of contact and co-ordination between research workers similarly engaged, (3) the observation and reporting of work in progress and (4) planning and arranging of future work.

Dr. E. F. Armstrong gave a lecture in memory of Murdoch tracing the growth of the gas industry and speculating on its prospects.

Non-technical readers would be interested in a paper by L. W. Andrew and A. Barrow on comfort heating by gas. To-day gas is being increasingly sold on two-part tariffs which encourage the freer use for major heating and raise the question as to the extent to which it can replace solid fuel for continuous heating. The advantages of cleanliness, flexibility and reduction of labour have long been recognized, particularly for intermittent heating. For central heating, solid fuels, especially coke, have appeared to show an unassailable advantage, but coal gas is increasingly entering this field when cleanliness, high rent and automatic control offer sufficient inducement. 'Central heat' is normally conveyed by means of hot water, but 'central' heat can more cheaply and simply be conveyed in a potential form as coal gas, and the problem to-day is to devise means for converting this into effective and acceptable sensible heat.

'T'he paper distinguishes between 'warmth' and 'comfort'. For comfort, it would appear to be desirable to have air at $50-60^{\circ} \mathrm{F}$. in movement without perceptible draught, supplemented by radiant heat received on the front of the body from an incandescent source. Shorter infra-red rays of length below $3 \mu$ capable of penetrating the skin, according to $\mathrm{L}$. Hill, are of particular value. In addition, tradition in Great Britain requires an open fire with the character associated with the open coal fire. The authors believe that these requirements can be met by 
combining 'background' heating by flueless appliances with suitable gas fires. For continuous domestic heating they think the radiating gas fire will take a new form, whether in some measure resembling the coal fires of the past-as it may in the near futureor taking a more revolutionary form. In support of this view they exhibited a gas fire of new design such that any ordinary person walking past would take it for a coal fire of conventional type. Instead of the formal geometrical radiants, it exhibited a face of black mass enclosing glowing cavities surmounted by a play of real flames. There must be many to-day who would find it worth while to pay something extra for the merits of a coal fire without its demerits.

For commercial buildings new designs of overhead radiating panels-both high and low temperature radiators-are now available. In factories, the 'unit heater' which provides a stream of warm air directionally propelled offers many advantages. All these offer considerable advantages over central heating by circulation of hot water, and the paper suggests that great developments may be expected in gas heating.

H. J. Hodsman.

\title{
Structure of Trilobites
}

\author{
By Dr. W. T. Calman, C.B., F.R.S.
}

\begin{abstract}
$\mathrm{T}$ HE trilobites are generally recognized as occupying a key position in relation to the phylogeny of arthropods, and until we have some certainty as to their structure and relationships it is not possible to speculate profitably about the mutual affinities of insects, crustaceans and arachnids. In the course of the last sixty years, a great deal of information regarding their appendages has been obtained, for the most part by American palæontologists; but the results of different investigators have not been easy to reconcile and very divergent conclusions have been drawn regarding the systematic position of the group.
\end{abstract}

Dr. C. D. Walcott, who was the first to obtain definite information about the appendages, worked chiefly on the Ordovician genus Ceraurus, which he studied in thin sections. Dr. C. E. Beecher (whose final memoir was completed after his death by his pupil, P. E. Raymond) studied abundant material of Triarthrus, from the same epoch, as exposed in surface view by splitting the rock. The results of these two workers seemed to reveal an extraordinary difference of structure in the limbs of the two genera. The legs of Ceraurus were provided by Walcott with a pair of corkscrew-shaped gills attached near the base, while those of Triarthrus, according to Beecher, were simply biramous, with the outer branch segmented and fringed on one side with flattened filaments. Taking up the subject again towards the end of his life, Walcott maintained that the spiral 'gills' really existed but now allotted only one of them to each limb and provided it with a row of flattened filaments like those described by Beecher in Triarthmes. In a review of Walcott's paper ${ }^{1}$, I pointed out that the row of filaments, attached to the successive turns of an open helical spiral, would not remain in one plane as they are seen to do in the fossils, unless the spiral were rigid to an improbable degree.

Dr. Leif Størmer, in an important memoir ${ }^{2}$, discusses the whole subject in the light of a re-examination of Walcott's and Beecher's preparations. He has also applied Sollas's method of serial grinding and reconstruction to Ceraurus, and has obtained some very interesting and convincing results. In the first place, the fundamental differences which Walcott supposed to exist between the appendages of Ceraurus and Triarthrus have disappeared. The spiral structures are proved to depend on misinterpretation of the sections. In Ceraurus, as in Triarthrus, the appendages are simply biramous, with an outer branch consisting of a segmented stem fringed on one side with a single row of flattened rod-like or filamentous structures which may, or may not, have served as gills. In view of the poor state of preservation of the appendages in Ceraurus and the obscurity of the traces that they have left in the rock, it is not surprising that many details of their structure must remain uncertain, but Størmer appears to be justified in claiming that all the trilobites so far studied have appendages built on the same plan. Beyond this, however, his far-reaching deductions can only be treated with much reserve.

Impressed with his discovery in Ceraurus (and, very doubtfully, in other genera) of a 'precoxal' segment to which the outer branch of the limb is attached, he designates this outer branch 'preepipodite' and deduces from this that the trilobites have no close relationship with the erustacea but are, on the other hand, intimately associated with the eurypterid-arachnid group. To do this, he has to minimize the importance of those characters in which the trilobites diverge from the Arachnida and approach the Crustacea. To anyone with a sense of morphological values, however, the flagelliform preoral antennules, the five pairs of biramous gnathobase-bearing head appendages following them, and the furcal filaments (of Neolenus) far outweigh the fact that the peduncle of the biramous limbs is unsegmented, as it is, by the way, in not a few Crustacea.

The resemblances between trilobites and primitive arachnids have been often pointed out and are generally admitted, but Størmer does not strengthen his case by taking seriously Schultze's far-fetched comparisons between trilobites and ticks (Ixodidæ). To reason from fortuitous and isolated coincidences of structure is to play into the hands of those who are so ready nowadays to proclaim the bankruptcy of morphology and phylogeny. Anyone who is tempted by such slapdash methods may be recommended to consider the numerous and striking resemblances between trilobites and isopod Crustacea, and then to study carefully the evidence for the derivation of the Isopoda from primitive Mysidacea, which have scarcely anything in common with trilobites except that they are arthropods.

' Geol. Mag., 58, 553 (1922).

2 Studies on Trilobite Morphology. Part I. The Thoracic Appendages and their Phylogenetic Signiflcance".' (Norsk Geol. Tidz8kr., 19, 143-723, 12 pls., text-figs.) 